\title{
Perspectives on the Thematic Analysis of Scientific Thought
}

\section{Citation}

Holton, Gerald. "Perspectives on the Thematic Analysis of Scientific Thought." In Victory and Vexation in Science: Einstein, Bohr, Heisenberg, and Others, 135-151. Cambridge: Harvard University Press, 2005.

\section{Published Version}

http://www.hup.harvard.edu/catalog.php?isbn=9780674015197

\section{Permanent link}

http://nrs.harvard.edu/urn-3:HUL.InstRepos:37894289

\section{Terms of Use}

This article was downloaded from Harvard University's DASH repository, and is made available under the terms and conditions applicable to Other Posted Material, as set forth at http:// nrs.harvard.edu/urn-3:HUL.InstRepos:dash.current.terms-of-use\#LAA

\section{Share Your Story}

The Harvard community has made this article openly available.

Please share how this access benefits you. Submit a story.

\section{Accessibility}




\title{
Perspectives on the Thematic Analysis of Scientific Thought
}

\author{
Gerald Holton
}

It is now over four decades that I first published on the concept of a thematic analysis of scientific thought (in Eranos-Jahrbuch of 1962). The approach laid out there and in the book published by Harvard University Press in 1973 (revised edition, 1998) has been at the heart of much of my subsequent research and publications, as well as having been taken up by others. It may therefore be appropriate to look back and present a personal perspective on this subject.

Under that sign, the first thing must be a confession. Studying the thematic origins and elements in scientific works, with its focus on the personal presuppositions, especially in the nascent stages, was not at all an activity for which I was prepared by my early education and beliefs. On the contrary. My early intellectual formation might be said to have taken place under the auspices of a kind of positivism which took for granted, in Hans Reichenbach's famous phrase, that one should be "interested not in the context of discovery, but in the context of justification."

My doctoral thesis, on experimental high pressure physics, was done under the supervision of P. W. Bridgman, who, besides being a Nobel Prize physicist, was also deeply interested and active in philosophy. That contribution came to be known under the name of Operationalism, a version of Pragmatism/Instrumentalism, with its deep roots in American philosophy of science. His Logic of Modern Physics (1927) and his many subsequent articles were extraordinarily influential, especially in the U.S. and far beyond the natural sciences.

I also was taking courses on philosophy, including one on the philosophy of science given by the physicist-philosopher Philipp Frank, and was then asked by him to be his assistant, 
and became a close friend and colleague. Frank had been one of the pillars of the Vienna Circle, and from 1939 on, brought the Unity of Science movement and logical empiricism to the United States, making Cambridge its most active center. The monthly meetings of his group was active for about a decade, attracting scholars from other parts of the United States to Cambridge. I took part in its sessions, having been invited to be the Secretary of the group--an appropriate position for the person who was by far the youngest in the room. In addition to all these possible influences upon me, there also was the magisterial Richard von Mises in the Applied Science Department, next to ours—a powerful missionary, who had targeted me to translate into English his book on Positivism. (I mustered the courage to decline that, and I am sure he never forgave me.) W. V. Quine, one of the participants in the monthly meetings, described these in his autobiography, Time of My Life: An Autobiography (1985, p. 219), as the "Vienna Circle in Exile." 1

One might have expected that I, living in this ambiance for many years, would become a disciple of later-style Positivism. What was it that prevented such a development, so contrary to the ideas of my distinguished early sponsors, colleagues, and friends? In retrospect, I see that a seed of my later interests appeared, perhaps to my own surprise, in my earliest historical study, on Johannes Kepler's torturous way to his three great Laws. ${ }^{2}$ The data Kepler had to work with--the phenomenic dimension--and the logical/analytical system he brought to bear on the interpretation, formed, so to speak, the $x$-y-axes of the plane of discourse of his science, as we see it also in its modern form, in the published scientific papers. But in addition, I found that Kepler was highly motivated and helped, or sometimes hindered, by a third type of approach, a third (z) dimension,

\footnotetext{
${ }^{1}$ I have described the genesis and fortunes of the group and its meetings, in chapter 1 of my book Science and Anti-Science (see list of books at end), and in the essay "On the Vienna Circle in Exile: An Eyewitness Report" in W. De Pauli-Schimanovich, et al. (eds), The Foundational Debate (Kluwer Academic Publishers, 1995, pp. 269-292).

2 It was published in the American Journal of Physics in 1956 under the title "Johannes Kepler's Universe: Its Physics and Metaphysics" (and reprinted in chapter 2 of Thematic Origins).
} 
orthogonal to the other two. In his case, that third dimension was populated with hardy presuppositions that were neither confirmable nor falsifiable, not arising from the data or the theory, but imposed on them by him from the outset, accepted explicitly or implicitly, until the end, or until he found that they had to be replaced after all by other presuppositions.

Among these presuppositions which formed the thematic framework within which he labored over his data and calculations, one finds his belief that three-dimensional Platonic bodies are a key to the explanation of distance between planetary orbits; the old hantisement of the circle as another such key; then from 1605 on, as he put it, "that the celestial machine is to be likened not to a divine organism but rather to a clockwork." And, finally, his brilliant superposition of the cosmological model in terms of three themata: the universe as physical machine, the universe as mathematical harmony, and the universe as central theological order.

My growing interest in the history and philosophy of science in those years was being furthered by teaching physics courses in the new General Education program at Harvard which, not least through the interest and participation of the President of the University himself, James Bryant Conant, were based on the science history of the topics being taught.

But the most powerful force to change my intellectual career came almost by accident, not long after Albert Einstein's death in 1955. Philipp Frank had been a close friend and biographer of Einstein, his successor at the German University in Prague in 1912, at Einstein's recommendation. He suggested I might prepare some historical account of aspects of Einstein's work, to be used at a Memorial Service. To my astonishment, I found that there was then hardly any work being done by historians of science on Einstein's fundamental advances, although there existed more than enough biographies. In Chapter 2, I recounted my introduction to the Einstein Estate, my initial visit to the Institute at Princeton to see if there was some first-hand material on which to base an historical essay, and my subsequent immersion in Einstein's correspondence and manuscripts held there. 
The main point of interest for my account here is that because of my being able to read Einstein's drafts of his work and copies of his correspondence, it became evident that here, too, in addition to his attention to data and logical/analytical tools (to which Einstein himself referred to as the "empirical" and the "rational" aspects), a mainspring of his work was often a set of fiercely held presuppositions, what I had identified as thematic elements. Among the themata which guided Einstein's theory construction were clearly the following: the primacy of formal, rather than materialistic explanation; unity or unification; logical parsimony and necessity; symmetry; simplicity; causality in the classical sense; completeness in the subordination of every phenomenon under the respective theory; the continuum; and of course constancy and invariance.

Once seen clearly in the nascent stages, these thematic components can sometimes, with some effort, be observed also in the published papers, although Einstein, like most scientists, took care to keep such motivating, seemingly metaphysical aspects out of view. The hold of these on his wide-ranging imagination explains why he would obstinately continue in a given direction even when testing against experience (as in both special and general relativity theory) was initially unavailable or difficult, and why, on some occasions, he held fast even contrary to recent experimental results. It explains also what to some commentators have been persistent puzzles: why Einstein was hostile to theories well supported by correlation with experiments but based on thematic presuppositions opposite to his own (as in the case of quantum mechanics of Niels Bohr's school, with its emphasis on discontinuity, probabilism, and incompleteness in the description of phenomena); and why to him Michelson's experiments were not crucial in the genesis of the relativity theory).

Philosophers of science had overlooked Einstein's pilgrimage from a self-confessed follower of Ernst Mach's ideas to a position much closer to that of Max Planck. Indeed, one of these, a distinguished student of Hans Reichenbach, chided Einstein in print in no uncertain terms for not having acknowledged what his critic took to be a crucially necessary experimental support for Einstein's initial proposal of the principles of relativity theory. 
My first public attempt to present my view of Einstein's work came in 1958 at the International History of Science meeting in Barcelona. ${ }^{3}$ A more extensive investigation of the powers and limits of thematic analysis was delivered in 1961 at one of the Eranos conferences in Ascona, on Lago Maggiore. That seemed to me the safe place to try out my ideas at length, because those annual conferences had two charming properties: In the morning one could lecture as much as three hours before a small but excellent audience (typically including Gershom Scholem, Herbert Ried, Karl Deutsch, Hans Richter, and other scholars and artists) who then participated, in the afternoon, in another lengthy period of questions and discussion. Secondly, the Proceedings were published in a very small- circulation volume-which accounts for my daring to entitle my talk "About the Hypotheses on which are based the Natural Sciences," ${ }^{4}$ boldly referring to the famous Habilitationsvortrag of Bernard Riemann, who had died a century earlier in a town on the same lake.

You might wonder, as indeed I did, what my colleagues back in Cambridge would think about my conceptions, which I shared with them in manuscript, as a sort of declaration of independence; but they were generous and forgiving. In any case, I felt that I was now launched on fruitful work, publishing aspects of thematic analysis in case studies that were collected in the book of 1973, focusing on aspects of the contributions by Kepler, Newton, Niels Bohr, and Einstein. In later publications, I also turned to others, including Galileo, Fermi, R. A. Millikan, and Heisenberg. ${ }^{5}$

3 "Continuity and Originality in Einstein's Special Relativity Theory," Actes du IXe Congres Internationale d'Histoire des Sciences, Barcelona, 1959.

4 "Ueber die Hypothesen, welche der Naturwissenschaft zu Grunde liegen," in Adolf Portmann (ed.), Eranos-Jahrbuch XXXI/1962 (Zurich: Rhein-Verlag, 1963, pp. 351-425). 5 The concept of subjecting scientific work to thematic analysis was discussed and taken up by others, as mentioned in the Postscript to the 1988 edition of Thematic Origins (such as R. K. Merton, Erik Erikson, Roman Jakobson, Robert Nisbet, Helge Kragh, John Losee), as well as a number of others since that date, including Peter Galison and S. S. Schweber. 
Turning now from an autobiographical sketch to a review of the main points of the work itself, it may be helpful, especially for those who have not followed the books and articles in which the role of themata were dealt with, to outline the thematic approach, not least in order to clarify the distinctions with entirely different conceptions, such as archetypes, paradigms, or Kantian Categories.

To summarize essentials and to set the stage, consider that when scientists publish the results of their work in journals, textbooks, etc., they are submitting them for acceptance into what could be called Public Science, generally making quite sure to cast a veil over the prior stage of their effort, the scientist's individual activity during the nascent period, which deserves the term Private Science. The common error of using the word "science" without making this distinction can show up glaringly when the historian of science tries to understand the motivation of scientists for pursuing their research problems, the original choice of their conceptual tools, or the treatment of their data. In all these cases, one may discover that during the nascent, "private" period of work, some scientists, consciously or not, use highly motivating, very general thematic presuppositions. But when such work is then proposed for entry into the "public" phase of science, these motivating aids tend to be suppressed, and even disappear from view. Even though such thematic notions arise from a deep conviction about nature, on which the initial proposal and eventual reception or rejection of one's best work may be based, they are not explicitly taught, and they are not listed in the research journals or textbook. That has certain advantages, insofar as silence about personal motivations and thematic preferences avoids any deep, unresolvable disputes in the public phase. Consensus is easier to reach if thematic elements are kept out of sight.

Some modern philosophers of science, particularly those tracing their roots to empiricism or positivism, go further and assign "meaning" to any scientific statement only insofar as the statement can be shown to have phenomenic and/or analytic components in this plane. To be 
sure, this policy has freed science from innate properties, occult principles, and other tantalizing, "metaphysical" notions which cannot be resolved into components along those $x$ and $y$ axes. It was in part for the sake of this advantage that positivists and empiricists urged that the activity "science" be defined entirely in terms of sense observation and logical argument-a movement that grew out of courageous opposition to speculative, ungrounded, and metaphysical deadwood that was thought to infest the public science of their time.

Nevertheless, this two-dimensional view of science also has had its costs. It is not true to the behavior and experience of individuals engaged in research. It does nothing to explain why at any given time the choice of problems or the reception of theories may be strikingly different among individuals or like-minded groups who face the same corpus of data. (Examples on this point are the early, quite different responses to relativity in Germany, England, France, and the United States of America.) It also overlooks both the positive, motivating, and emancipatory potential of certain presuppositions, as well as the negative and enslaving role that sometimes has led promising scientists into disastrous error. For, again, Einstein and Niels Bohr were rather well matched in navigating the two-dimensional plane of science, as were Schrödinger and Heisenberg. Yet there were among them fundamental antagonies in terms of programs, tastes, and beliefs, with occasional passionate outbursts among the opponents. The thematic differences, which are at the core of such controversies, do sometimes break through—and they shatter the two-dimensional model.

Above all, this limited view does not explain what an historian, looking at laboratory notebooks or early drafts of distinguished scientists, can sometimes see with stark clarity the willingness of the scientists to what can only be called a suspension of disbelief about the possible falsification of their hypotheses that emerges from the data before them. Thus while the planar view is satisfactory for the scientists' intent on furthering advances in their field inductively, that view requires an amendment to help those who try to understand the original 
sources and pathways of the creative process. The various thematic ${ }^{6}$ propositions can be found to persist for a long time in the individual case, as well as throughout long periods of history. Many are widely shared, and in a given science such as physics they are and have been surprisingly few in number.

III

On this view—to elaborate the mnemonic device—a scientific statement is no longer, as it were, an element of area in the two-dimensional plane, but a volume element, an entity in threedimensional space, with components along each of the three orthogonal (phenomenic, analytic, and thematic) axes. The statement of two scientists are therefore like two volume elements that may not completely overlap and so may have differences in their projections, especially along the z-axis. Thematic analysis, then, can serve to identify the particular map of the various themata which, like fingerprints, can characterize an individual scientist or part of the scientific community at a given time. For Einstein one can discern the themata supporting his theory construction throughout most of his long scientific career (see, in the List at the end of the paper, especially book 2 (Thematic Origins), chapters 6-9; book 4, chapters 2-4; book 5, chapter 3; and book 6, chapters 7 and 9 .

Among other major scientists discussed in the books noted in the end-list, and whose work has lent itself to better understanding through thematic analysis, are Galileo (book 6, chapter 4), Thomas Young (book 6, chapter 4), Ernst Mach (book 2, chapter 7; book 5, chapters 1 and 2), A. A. Michelson (book 2, chapter 8), R. A. Millikan (book 3, chapter 2), Heisenberg (book 4 chapter 7), Erwin Schrödinger (book 2, chapter 4), J. Robert Oppenheimer (book 4, chapter 7), Max Planck (book 5, chapter 3), and Steven Weinberg (book 3, chapter 1). In other publications I have discussed other scientists. Thematic analysis in teaching the history of

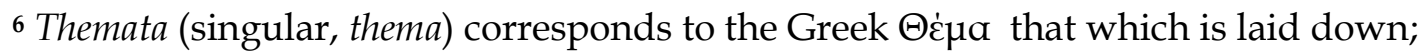
proposition; primary word. 
science, discussed in the fifth chapter of book 6, is shown there to be one of nine conceptual tools needed for a full understanding of an event or a case in the history of science.

These studies have shown that themata embraced by opposing scientists often appear in opposing dyads, symbolized by $\Theta /$ anti $\Theta$. Examples are: continuum (e.g., in field) versus discontinuum (e.g., in atomism); complexity/simplicity; reductionism/holism; unity/hierarchical levels; causality/probabilism; analysis/synthesis. There are also a few triads, such as evolution/steady state/devolution, or mechanistic/materialistic/mathematical models. While I have studied primarily themata in physical science, the same findings appear to be applicable also to the other sciences. A list of those found so far can be constructed from the indexes of the books listed at the end, under "thema" and "themata."

The thematic elements of scientific thought become visible most strikingly during a conflict between individuals or groups that are committed to opposing themata, or within the developing work of a scientist holding on to a thematic concept for as long as possible, until forced to switch to the anti-thema (as in the case of Millikan, on the photoelectric effect; or in the case of Max Planck and the quantum). It is impressive that research has led to the finding that only a relatively small number of themata and anti-themata-perhaps of the order of one hundred-have sufficed throughout modern science. The contrary themata of Heraclitus and Parmenides are still in use. This is one reason to avoid the word "theme" in place of thema, for as in music there is no limit to the number of possible themes, there is no longevity, nor any overarching generality that can be drawn from them for science.

Additions - such as the introduction of the thematic notion of complementarity in the 1920s_are rare. To be sure, a scientific concept such as "atom" has changed over and over again, from Democritus to this day. But what has not changed is the thematic concept of discreteness underlying atomism, which expresses itself in the same way in the ever-changing notion of "atom." That, in brief, is one of the reasons I am not convinced of the theory of the "incommensurability" of theories. 
At the same time it also should be pointed out that some scientists function very well without allegiance to a set of thematic ideas, while others are led into error by holding fiercely to an inappropriate thematic idea (Mach, book 5, chapter 2; Felix Ehrenhaft, book 3, chapter 2). Of course not all themata are meritorious. As Francis Bacon warned in discussing the four Idols that can trap the scientific mind, some have turned out to divert or slow the growth of science. Nor have all sciences benefited equally; the holistic viewpoint introduced early in the nineteenth century had advantages in physics, but was on the whole a handicap for biology. Also, it should not be necessary to stress that thematic analysis, which arose out of an empirical study of actual scientific work, is not an ideology, a school of metaphysics, a plea for irrationality, an attack on the undoubted effectiveness of empirical data and experimentation, or a means for teaching scientists how to do their job better.

IV

We can turn now to one of the puzzles facing every scientist and historian of science. If, as Einstein and others have claimed, the concepts of science are free inventions of the human mind, should that not allow an infinite set of possible thematic axiom systems clamoring for use in constructing a theory to which one's mind could leap or cleave? Virtually every one of these systems would ordinarily be useless for fashioning a theory to encompass the phenomena being studied. How then could there be any hope of success except by chance? The answer must be that the license implied in the leap to an axiom system by the freely inventing mind is the freedom to make a leap, but not the freedom to make any arbitrary leap whatever. The choices available are narrowly circumscribed by a scientist's particular set of themata that filters, constrains, and shapes the style, direction, and rate of advance on novel ground. (See book 4, chapter 2.) And insofar as the individuals' sets of themata overlap, the progress of the scientific community as a group is similarly constrained or directed. Otherwise, the inherently anarchic connotations of "freedom" could indeed disperse the total effort. 
Since science is ever unfinished, what is functional in a given field may reveal itself not to be so in the future, and hence there may be a flux of thematic allegiance by the community. The analysis of thematic elements in theories is descriptive, not prescriptive. It may turn out for example that the powerfully motivating quest for a general synthesis, so successful from Oersted to Maxwell and from Einstein to our day, could be a trap, as Isaiah Berlin warned in his book Concepts and Categories. Himself a dedicated pluralist, Berlin christened the drive toward any grand synthesis the "Ionian Fallacy," so designating the search, from Aristotle to our own day, for the ultimate constituents of the world in some non-empirical sense.

Superficially, the seekers of unified physics, particularly in their monistic exhortations, may seem to have risked falling into that trap-from Copernicus, who confessed that the chief point of his work was to perceive nothing less than "the form of the world and the certain commensurability of its parts," to Max Planck, who exclaimed in 1915 that "physical research cannot rest so long as mechanics and electrodynamics have not been welded together with thermodynamics and heat radiation," to today's string theorists in physics who seem to be offspring of the founding father of science among the ancient Greeks, Thales himself, in their insistence that one entity will explain all. But the scientific profession as a whole has been rescued over the years from becoming mired in such traps, as might well be caused by devotion to a single thema. In practice there is at any time enough variety of commitments—-for example, in this case, the existence of a group which in recent years is willing to settle for a pluralistic physics, with a hierarchical set of levels (see some of the publications by Victor Weisskopf and Philip Anderson).

Diversity in the spectrum of themata held by individuals at a given time, and overlap among these finite sets of themata (rather than "anything goes")—-that is a formula which answers the question why the preoccupation with trying to achieve, say, a unified world picture, did not lead science to a totalitarian disaster, as an Ionian Fallacy by itself could well have done, nor lead 
to an anarchic dispersal of the efforts of the community, nor to a "random walk" without progress, as the paradigm theory of science held at least initially.

At every step, each of the various scientific world pictures in use is generally considered a preliminary version, a premonition of the Holy Grail. Moreover, each of these various, hopeful but incomplete world pictures that guide scientists at a given time is not a seamless, unresolvable entity. Nor is it usually completely shared even within a given subgroup (in both respects, again, unlike a "paradigm"). Each member of the group is apt to operate with a specific set of separable themata. Einstein and Bohr agreed far more than they differed, even though they had profound thematic incompatibilities. Also, most of the thematic currents at any time are not newly minted, but adapted from predecessor versions of the world picture, just as many of them will later be incorporated in subsequent versions, as they evolve further.

With this model of the role which thematic components play in the advancement of science, we can understand why scientists need not hold substantially the same set of beliefs to communicate meaningfully with one another in either agreement or disagreement, and yet contribute to the cumulative, generally evolutionary improvement of the state of a science. Scientists' beliefs have considerable fine structure; and within that structure there is room both for thematic overlap and agreement, which generally have stabilizing effect, and for intellectual freedom, which may be expressed as thematic disagreements.

Innovations emerging from even "far-reaching changes," as Einstein termed the contributions of Faraday, Maxwell, and Hertz, very rarely require from the individual scientist or from the scientific community the kind of radical and sudden reorientation implied in such terms as Gestalt switch, revolution, discontinuity. On the contrary, by far, most innovations are coherent with a model of evolutionary scientific progress to which most scientists explicitly adhere, and which emerges also from the actual historical study of their work. Not being constrained to the two-dimensional plane alone, they engage in an enterprise whose saving pluralism resides in its many internal degrees of freedom. What does save science from falling 
victim to inappropriate presuppositions held for long are the chastening roles both of the coordination with experiment and of the multiple cross-checks of any finding by other scientists who themselves may have started with quite different presuppositions. Thus we can understand why scientific progress is often disorderly, but not catastrophic; why there are many errors and delusions, but not one great fallacy; and how mere human beings, confronting the seemingly endless, interlocking puzzles of the universe, can advance at all in the task of understanding it.

V

Among the costs of the old, two-dimensional definition of "science" has long been a popular image of that pursuit which treats it as if it were a cold and lifeless imposition of an authoritarian, dogmatic excess of rationalism, one that left no room for the creative play of the intuition or personal preferences (see book 6, chapters 1 and 2). But when one adds the role of the thematic dimension in actual research and in the acceptance and rejection of theories, this image is shown to be quite false. The corrected version also explains the exaltations, from Kepler's ecstasy to the response to Schrödinger's physics by those who shared his thematic propensity for continua (“a fulfillment of that long-baffled and insuppressible desire," as K. K. Darrow put it)—and their opposites, the expressions of dislike and despair, which pepper the confessions of scientists. Thus Werner Heisenberg, a master of discontinuum concepts, wrote famously, "The more I ponder the physical part of Schrödinger's theory, the more disgusting it appears to me."

Here we touch also on the fact that the aesthetic and motivational value of themata in science shows that the role of such themata is not so different from the guiding presuppositions and framing worldviews expressed in other creative activities, from the arts to politics. More than that, some themata in a particular science are exemplifications of the same fundamental themata in other sciences, or even in cultural productions far from that of the sciences as such. Take Niels Bohr's complementarity principle as an example. As Bohr himself explicitly noted, he 
saw complementarity in physics as an expression of one general thema in that relatively small pool of themata from which the human imagination draws for all its endeavors. It is not the case that such an expression is in some way a pale reflection or vague analogy of a principle that is basic only in quantum physics. On the contrary, the situation in quantum physics is a reflection of an all-pervasive principle. Whatever the most prominent factors were which contributed to Bohr's original formulation of the complementarity point of view in physics—-whether his physical research, or thoughts on psychology, or his reading in philosophical problems, or the controversy he witnessed between rival schools in biology, or the complementarity demands of love and justice in everyday dealings, to which he often referred-it was the universal significance of the role of complementarity which Bohr came to emphasize, to the very end, indeed, even in his interview one day before his death.

Generalizing the case we may say that each special statement of a certain thema is an aspect of its more general conception. Thus a general thema $\Theta$ would take on a specific form in physics that may be symbolized by $\Theta \varphi$, in studies on mythology and folklore by $\Theta \mu$, and so on. The general thema of discontinuity or discreteness, for example, thus appears in physics as the $\Theta \varphi$ in discussions on atomism, whereas in psychological studies it appears as the thema $\Theta \psi$ of individualized identity. Similarly, the multiple appearances of the $\Theta$ of evolution is evident, in different guises, in fields ranging from biology to cosmology, from embryology to economics. One may therefore express any given general $\Theta$ as the sum of its specific exemplifications. Hence it is reasonable to expect that thematic analyses, such as those described in the publications cited in the book list, would be found useful also in a large variety of other fields of study. And in fact 
this is what has been happening, as I referred to in the Postscript to the 1988 edition of the Thematic Origins book. ${ }^{7}$

For pedagogic purposes, the scientific content of curricula has been arranged largely along thematic lines in two national projects, one from the American Association for the Advancement of Science: Project 2061, Benchmarks for Science Literacy (New York: Oxford University Press, 1993), and the other in F. J. Rutherford and A. Ahlgren, Science for All Americans (New York: Oxford University Press, 1990).

The wide range of these fields bears witness to the fact that there is a much greater commonality of intellectual and motivational resources across areas than is generally acknowledged. The frequently asserted dichotomy between science and humanistic scholarship or productions, while real at many levels, is far less convincing if one looks carefully at the usefulness of the thematic materials in all of these.

VI

Finally, a word about other concepts which occasionally are confused with thematic propositions. One is metaphors and related notions such as mental models, frames, and schemata. The metaphoric imagination in science is a lively component of it, alongside others, such as the visual and the thematic (see particularly book 2, chapter 9, and chapter 4 in book 6). But as even its original Greek definition implied, metaphor, unlike themata, serves the traditional function of making conceptual connections between selected similarities; moreover, they are in principle infinite in number.

${ }^{7}$ Encyclopedia entries on thematic analysis include Allen Kent (ed.), Encyclopedia of Library and Information Science, vol. 61, Supplement 6 (New York: Marcel Dekker, 1987, pp. 332-339), the entry for Thema (Themata) in the Dictionnaire d'Histoire et Philosophie des Sciences (Paris: Presses Universitaires de France, 1999), and the brief survey in J. L. Heilbron, ed., The Oxford Companion to the History of Modern Science (Oxford: Oxford University Press, 2003, p. 741). 
As noted, another potential confusion with themata involves the concepts of "paradigm." But the latter, as usually presented, refers primarily to a social phenomenon in the scientific profession; the "paradigm, it is said," does not generally come fully into being until exemplified by the supposedly pervasive acceptance of a particular framework of thought in a speciality. However, we are told that sooner or later its time is up, and another of a potentially infinite number of other paradigms holds sway, until in its turn it, too, is eventually removed in some discontinuous, revolutionary development. (As for one of the main arguments made for that idea, i.e., the presumed revolutionary character of relativity theory, Einstein himself always rejected being thought a scientific revolutionary.) By contrast, a thema is found in individual work, as part of an individual's spectrum of themata that no one else may have accepted in toto; also, as indicated, themata are found to be finite in number and generally of long duration, and so accentuate the longevity and evolutionary nature of scientific advance.

It may not be necessary to stress here that it is inappropriate to associate themata with Platonic or Jungian archetypes, not least since those, unlike thematic analysis, did not arise from an empirical study. However, there may be a link between individual research styles and the embrace of a particular set of themata. Thus Kurt Lewin identified Aristotelian versus Galilean individual modes of thought, and showed their persistence in contemporary scientific work. A. C. Crombie (in Styles of Scientific Thinking in the European Tradition, London: Duckworth, 1994) has analogous, interesting case studies on six styles (postulational, experimental, hypothetical, taxonomic, probabilistic and statistical, and historical or genetic).

Among the concepts that may be confused with themata, the most obvious is what Immanuel Kant, following Aristotle, called "Categories." Examples he gave in his Critique of Pure Reason involved unity/plurality/totality; possibility/impossibility; existence/nonexistence; necessity/contingency. Apart from other obvious differences, Kant's "Categories" were, as he insisted, to be accepted as "pure concepts of the understanding which apply a priori to objects of intuition in general." 
Einstein agreed that the mind uses something that might be called categories or schemes of thought, needed in order "to find our way in the world of immediate sensations." He regarded them as necessary presuppositions for every kind of thinking about the physical world, and stated curtly, "Thinking without the positing of categories and concepts in general would be as impossible as is breathing in a vacuum." ${ }^{\mathbf{8}}$ But Einstein also insisted on an essential difference which shows that those categories are not Kant's concepts, but instead are quite close to thematic propositions. He insisted that his categories are not unalterably a priori, conditioned by the very nature of our mind; rather, they arise from and are subject to change by the unfettered imagination, and are "free conventions," justified only by their usefulness. As he puts it, the selection of "'categories' or schemes of thought...is in principle entirely open to us, and whose qualification can only be judged by the degree to which their use contributes to making the totality of the content of consciousness 'intelligible."' Therefore, it is possible that, far from being frozen into any position a priori, some scientists have, as noted, changed their thematic allegiances dramatically. (For example, Planck turned from an early Machist to an opponent, and Wilhelm Ostwald first rejected and then accepted atomism in chemistry.)

We end by noting an unsolved puzzle: what is the source of a person's particular set of thematic concepts and hypotheses? It is possible that the origin of themata in individual cases will someday be approached through studies of the nature of perception and apperception, and essentially of the psychodynamics of the development of concepts in early life. But for our part, the task continues to be the study of the rôle played by recurring general themata, among individual scientists and the profession as a whole.

\footnotetext{
8 Einstein, "Reply to Criticisms," in Paul A. Schilpp (ed.), Albert Einstein, Philosopher Scientist (pp. 673-74, 1949), pp. 937-940.
} 
List of books referred to:

(1) "Ueber die Hypothesen, welche der Naturwissenschaft zu Grunde liegen," in Adolf Portmann (ed.), Eranos-Jahrbuch XXXI/1962, Der Mensch, Führer oder Geführter im Leben (Zurich: Rhein-Verlag, 1963, pp. 351-425).

(2) Holton, Gerald Thematic Origins of Scientific Thought: Kepler to Einstein (Cambridge:

Harvard University Press, 1973 rev. ed., 1988).

(3) ------The Scientific Imagination (Cambridge: Harvard University Press, 1998).

(4) ------The Advancement of Science, and its Burdens (Cambridge: Harvard University Press, 1998).

(5) ------Science and Anti-Science (Cambridge: Harvard University Press, 1993).

(6) ------ Einstein, History, and Other Passions (Cambridge, Harvard University Press, 2000). 